\title{
Surgical results of cranioplasty with a polymethylmethacrylate customized cranial implant in pediatric patients: a single-center experience
}

\author{
*Pietro Fiaschi, MD, ${ }^{2,5}$ Marco Pavanello, MD, ${ }^{1}$ Alessia Imperato, MD, ${ }^{1}$ Villiam Dallolio, MD, ${ }^{3}$ \\ Andrea Accogli, MD, ${ }^{1,4}$ Valeria Capra, MD, ${ }^{1}$ Alessandro Consales, MD, ${ }^{1}$ Armando Cama, MD, ${ }^{1}$ and \\ Gianluca Piatelli, MD1
}

'Department of Pediatric Neurosurgery, Istituto Giannina Gaslini, Genoa; ${ }^{2}$ Department of Neurosurgery, San Martino - IST University Hospital (IRCCS), Genoa; ${ }^{3}$ Department of Neurosurgery, ICCS Hospital, Milan; ${ }^{4}$ University of Genoa; and ${ }^{5}$ Department of Neuroscience, University of Turin, Italy

OBJECTIVE Cranioplasty is a reconstructive procedure used to restore skull anatomy and repair skull defects. Optimal skull reconstruction is a challenge for neurosurgeons, and the strategy used to achieve the best result remains a topic of debate, especially in pediatric patients for whom the continuing skull growth makes the choice of material more difficult. When the native bone flap, which is universally accepted as the preferred option in pediatric patients, is unavailable, the authors' choice of prosthetic material is a polymethylmethacrylate (PMMA) implant designed using a custom-made technique. In this paper the authors present the results of their clinical series of 12 custom-made PMMA implants in pediatric patients.

METHODS A retrospective study of the patients who had undergone cranioplasty at Gaslini Children's Hospital between 2006 and 2013 was conducted. A total of 12 consecutive cranioplasties in 12 patients was reviewed, in which a patientspecific PMMA implant was manufactured using a virtual 3D model and then transformed into a physical model using selective laser sintering or 3D printing. All patients or parents were administered a questionnaire to assess how the patient/parent judged the aesthetic result.

RESULTS Patient age at craniectomy ranged from 5 months to 12.5 years, with a mean age of 84.33 months at cranioplasty. The mean extension of the custom-made plastic was $56.83 \mathrm{~cm}^{2}$. The mean time between craniectomy and cranioplasty was 9.25 months. The mean follow-up duration was 55.7 months. No major complications were recorded; 3 patients experienced minor/moderate complications (prosthesis dislocation, granuloma formation, and fluid collection).

CONCLUSIONS In this patient series, PMMA resulted in an extremely low complication rate and the custom-made technique was associated with an excellent grade of patient or parent satisfaction on long-term follow up.

http://thejns.org/doi/abs/10.3171/2015.10.PEDS15489

KEY WORDS cranioplasty; polymethylmethacrylate; custom-made technique; pediatric reconstructive surgery

$\mathrm{C}$ RANIOPLASTY is well established as a reconstructive procedure in restoring skull anatomy and repairing skull defects. The causes of skull defects are well known and may be acquired or congenital. Skull defects may produce disturbing deformity, lack of brain protection, and a variety of symptoms such as chronic headaches and mild developmental delay in young children. In ad- dition, the repair of cranial defects could provide relief to psychological drawbacks and increase social performance. Most commonly, cranioplasty in children younger than 3 years of age is performed to correct growing skull fractures and congenital anomalies, while in all age groups tumor removal and previous decompressive craniectomies are the most frequent reason for the defect. ${ }^{1}$

ABBREVIATIONS PMMA = polymethylmethacrylate .

SUBMITTED August 18, 2015. ACCEPTED October 23, 2015.

INCLUDE WHEN CITING Published online January 29, 2016; DOI: 10.3171/2015.10.PEDS15489.

* Drs. Fiaschi and Pavanello contributed equally to this work. 
The optimal skull reconstruction remains a challenge for neurosurgeons, especially in pediatric patients, in whom the strategy choice, commonly based on the factors of biocompatibility and cosmetic result, is made even more difficult by the continuing skull growth with age. Regarding biocompatibility, many autograft, xenograft, and allograft materials have now been used for cranioplasty. Many characteristics have been suggested to describe the ideal material for cranioplasty: biocompatibility features such as tissue tolerance, simplicity of manufacture, ease of sterilization, low thermal conductivity, radiolucency, light weight and biomechanical reliability, resistance to infections, no dilatability with heat, low cost, ready to use, etc., but there is no perfect material that fits all of these criteria. The various implant materials in use today are either autografts or allografts.

Autologous bone grafts offer superior resistance to infection and a decreased likelihood of extrusion but suffer from variable resorption, difficulties in reshaping, and donor-site morbidities. ${ }^{3,9,10,20}$ While autologous bone is widely used and favored in reconstructive procedures, synthetic alternatives are indicated in select cases, such those with severe bone graft resorption, bone comminution, infection, and limited donor site options. Over time, metals, ceramics, plastics, and recently, resorbable polymers and biomaterials have been used in craniofacial reconstructions.

Polymethylmethacrylate (PMMA) is a thermoplastic and transparent plastic and is the most frequently used material for allogenic cranial reconstructions with longterm results. Zander, in 1940, was the first physician to implant a methylmethacrylate prosthetic into a patient. ${ }^{17}$ Chemically, PMMA is commonly called acrylic glass or plexiglass. Methylmethacrylate proved to be superior to metals because of its light weight, low cost, malleability, radiolucency, and lack of thermoconduction. A disadvantage of PMMA is that it behaves in a brittle manner when loaded, especially under a strong impact force. Another disadvantage of this cement is that during polymerization it heats up to approximately $70^{\circ} \mathrm{C}$, therefore it is mandatory to remove the modeled PMMA cranioplastic in a deformable status with a small but residual risk of modifying the exact fitting of the implant. If the polymerization process takes place in situ, the surrounding tissue (dura mater or cortex) could be severely damaged due to the heat. ${ }^{2}$ The major advantage of PMMA is the flexible intraoperative application and the unlimited possibilities of adaptation to individual anatomy. In the majority of all cases PMMA cranioplasties are performed freehand. Solid PMMA is nonporous and does not allow for the ingrowth of native tissue; consequently, the integration with the surrounding tissue often necessitates the use of hardware to immobilize the implant. Porous PMMA is a modification of traditional PMMA that improved this aspect. It is composed of acrylic bone cement and an aqueous carboxymethyl cellulose gel. Histological analysis demonstrated that both hard and soft tissues are able to "grow" into the pores of the cement, thereby anchoring the implant to native structures, with evidence of bone ingrowth up to $4.5 \mathrm{~mm}$ into the prosthesis. ${ }^{5}$ In addition, porous PMMA, despite having $30 \%-40 \%$ less material than nonporous PMMA, offered no less impact resistance?

\section{Methods}

A retrospective study was conducted of the hospital records of patients who had undergone cranioplasty at Gaslini Children's Hospital between 2006 and 2013 (Table 1). A total of 12 consecutive cranioplasties using nonporous PMMA (SIAD Healthcare Tecres Cranos) in 12 patients were reviewed. The custom-made implants cost approximately 5 times as much as a noncustomized implant with PMMA. With the purpose of manufacturing a PMMA prosthesis using computer-aided design/computer-aided manufacturing, a digital subtraction mirror image technique with 1-mm-thick spiral CT scan data (using information from the contralateral side of the defect) was used. We considered the following contraindications for cranioplasty: the presence of hydrocephalus, infection, and brain swelling. The DICOM data were then downloaded to medical imaging visualization software for editing and $3 \mathrm{D}$ reconstruction to obtain a virtual 3D model of the skull.

Starting from a segmentation process, data on cranial curvature are obtained. With information about the curves of the shape of the affected side and the contralateral side of the skull, a model of closure of the defect is proposed. The curves obtained are then used as a framework on which the virtual solid model is produced. The virtual solid model is fused with the virtual model of the skull, to verify the correct coupling.

The virtual model is then read from a prototyping machine that builds the solid model section by section. This model is used to create the mold for the final step of the process. The PMMA is injected into the mold to obtain (after the polymerization) the final result ready to be sterilized (Figs. 1-3). All patients or parents provided written informed consent for this study.

The surgical procedure consists of reopening and following the previous incision and separating the epicranial tissues to the dura mater and to the osseous contour. In cases in which the prosthesis does not fit perfectly on the skull defect, it can be modified by drilling. The fixation is performed with mini plates or silk thread. To avoid epidural fluid collection the firm suspension of the dura mater is crucial. All patients were strictly followed-up with serial clinical evaluations at 7, 14, 21, and 28 days, a CT scan at 6 months after the surgery, and clinical evaluation 12 months later. All families were administered a questionnaire (proposed by Fischer et al.) $)^{8}$ to assess how the patient (or parent in very young patients) judged the aesthetic result (Table 2). The study was performed with approval from the Giannina Gaslini Institutional Review Board.

\section{Results}

Patient age at craniectomy ranged from 5 months to 12.5 years (mean 75.08 months) with a mean age of 84.33 months at cranioplasty. The mean time between craniectomy and cranioplasty was 9.25 months. There were 6 boys and 6 girls. All data concerning sex, age, etiology, and defect dimension were recorded (Table 1). The mean followup time was 55.7 months, ranging between 24 months (in one of the oldest patients of the series, almost 11 years old) and 96 months (in one of our youngest patients, 14 months old). Two patients were previously treated elsewhere with 
TABLE 1. Patients who underwent cranioplasty at Gaslini Children's Hospital (2006-2013)

\begin{tabular}{|c|c|c|c|c|c|c|c|c|c|}
\hline $\begin{array}{c}\text { Case } \\
\text { No. }\end{array}$ & Sex & Diagnosis & Location & $\begin{array}{c}\text { Age at } \\
\text { Craniectomy } \\
\text { (mos) }\end{array}$ & $\begin{array}{l}\text { Age at } \\
\text { Cranioplasty } \\
\text { (mos) }\end{array}$ & $\begin{array}{c}\text { Other } \\
\text { Cranioplasty }\end{array}$ & $\begin{array}{l}\text { Defect } \\
\text { Dimension } \\
\left(\mathrm{cm}^{2}\right)\end{array}$ & Complications & $\begin{array}{l}\text { FU } \\
\text { (mos) }\end{array}$ \\
\hline 1 & $\mathrm{~F}$ & Meningioma & $\begin{array}{l}\text { Frontoparietal } \\
\text { (bilat) }\end{array}$ & 140 & 148 & - & 82 & None & 84 \\
\hline 2 & $\mathrm{~F}$ & Osteoma & Lt parietooccipital & 14 & 34 & - & 48 & None & 96 \\
\hline 3 & $\mathrm{~F}$ & TBI & Lt parietal & 10 & 20 & - & 49 & None & 80 \\
\hline 4 & $\mathrm{~F}$ & Plagiocephaly & Lt frontoparietal & 70 & 75 & - & 35 & $\begin{array}{l}\text { Intracranial hypotension, } \\
\text { fluid collections }\end{array}$ & 73 \\
\hline 5 & M & TBI & Rt parietal & 100 & 109 & - & 55 & None & 55 \\
\hline 6 & M & Trigonocephaly & Frontal (bilat) & 5 & 34 & Later acrylic resin & 80 & $\begin{array}{l}\text { After } 6 \text { mos: head injury, } \\
\text { prosthesis dislocation, } \\
\text { removal \& new acrylic } \\
\text { implant }\end{array}$ & 58 \\
\hline 7 & $\mathrm{~F}$ & Fibrous dysplasia & Lt parietal & 150 & 155 & - & 61 & None & 53 \\
\hline 8 & M & TBI & Lt frontotemporal & 68 & 79 & $\begin{array}{l}\text { Previous parietal } \\
\text { bone splitting } \\
\text { (resorption) }\end{array}$ & 87 & $\begin{array}{l}\text { EEG alterations, anticonvul- } \\
\text { sant therapy, no crisis }\end{array}$ & 47 \\
\hline 9 & M & $\begin{array}{l}\text { Temporal AVM } \\
+ \text { aneurysm } \\
\text { (intracerebral } \\
\text { hematoma) }\end{array}$ & $\begin{array}{l}\text { Lt frontotemporo- } \\
\text { occipital }\end{array}$ & 54 & 58 & $\begin{array}{l}\text { Previous acrylic } \\
\text { resin (rupture) }\end{array}$ & 50 & $\begin{array}{l}\text { After } 2 \text { mos prothesis } \\
\text { dislocation, fixation w/ } \\
\text { resorbable plates \& } \\
\text { screws; after } 23 \text { mos } \\
\text { granuloma formation, } \\
\text { wound revision }\end{array}$ & 45 \\
\hline 10 & $M$ & Fibrous dysplasia & Lt occipital & 59 & 62 & - & 31 & None & 28 \\
\hline 11 & $\mathrm{~F}$ & Fibrous dysplasia & Rt hemispheric & 130 & 130 & - & 98 & None & 24 \\
\hline 12 & M & Histiocytosis & Rt pterional & 101 & 108 & - & 6 & None & 25 \\
\hline
\end{tabular}

$\mathrm{AVM}$ = arteriovenous malformation; $\mathrm{EEG}$ = electroencephalography; $\mathrm{FU}$ = follow-up; $\mathrm{TBI}$ = traumatic brain injury.

2 different techniques to cover the bone defect: 1 patient (Case 8) had parietal bone splitting that underwent resorption after 8 months, and the other patient (Case 9) had an initial acrylic resin cranioplasty that cracked after minor head trauma. All complications are reported in Table 1; all but 2 patients were treated conservatively.

One patient incurred prosthesis dislocation after a head trauma (Case 6). He underwent a new surgical procedure to replace the prosthesis. He was 39 months old at the time of the trauma, and only 5 months had passed since the cranioplasty, thus remanufacturing on the preexisting model was performed.

In another case (Case 9) the prosthesis underwent spontaneous dislocation; in the previous procedure, the prosthesis was fixed with absorbable sutures. At the second intervention, the same prosthesis was used and fixed with resorbable plates and screws. The same patient experienced a cutaneous foreign body granuloma, as a reaction to intradermal absorbable suture. He consequently underwent a cutaneous granuloma removal procedure and skin closure with silk sutures. Case 4 showed an extradural and subcutaneous fluid collection (probably due to the lack of surgical drain) with spontaneous recovery after a period of compressive bandaging.

The mean extension of the custom-made plastic was $56.83 \mathrm{~cm}^{2}$, with the smallest extension only $6 \mathrm{~cm}^{2}$ and the largest reaching $98 \mathrm{~cm}^{2}$. The aesthetic results, assessed through the questionnaire noted above, were judged as satisfying to very satisfying by all but 1 patient (Case 9 , wound revision due to a granuloma), with the implant size estimated as medium in 7 cases, small in 4 cases, and large in 1 case; the grade of satisfaction did not change over time except for Cases 6 and 9, whose implants were removed and replaced after dislocation. Medical complications related to cranioplasty are reported in Table 1 .

\section{Discussion}

Cranioplasty is a reconstructive procedure used to restore skull anatomy and repair skull defects. Optimal skull reconstruction is a challenge for neurosurgeons and the strategy to achieve the best result remains a topic of debate. There are 3 main determinants that influence the choice. The first is biocompatibility: many features should be evaluated, such as tissue tolerance, allergic reaction, early vascularization, possibility of intraoperative thermic damage, thermal conductivity, and resistance to infections. The second determinant is the cosmetic result. Regarding the aesthetic outcome, an important innovation in the cranioplasty technique had been achieved with the novel method of rapid prototyping, developed in the past few decades. This method offers the possibility of preoperatively forming various materials into custom-made implants to precisely fit each individual's cranial defect. This procedure has been demonstrated to not significantly increase the overall treatment cost, together with 


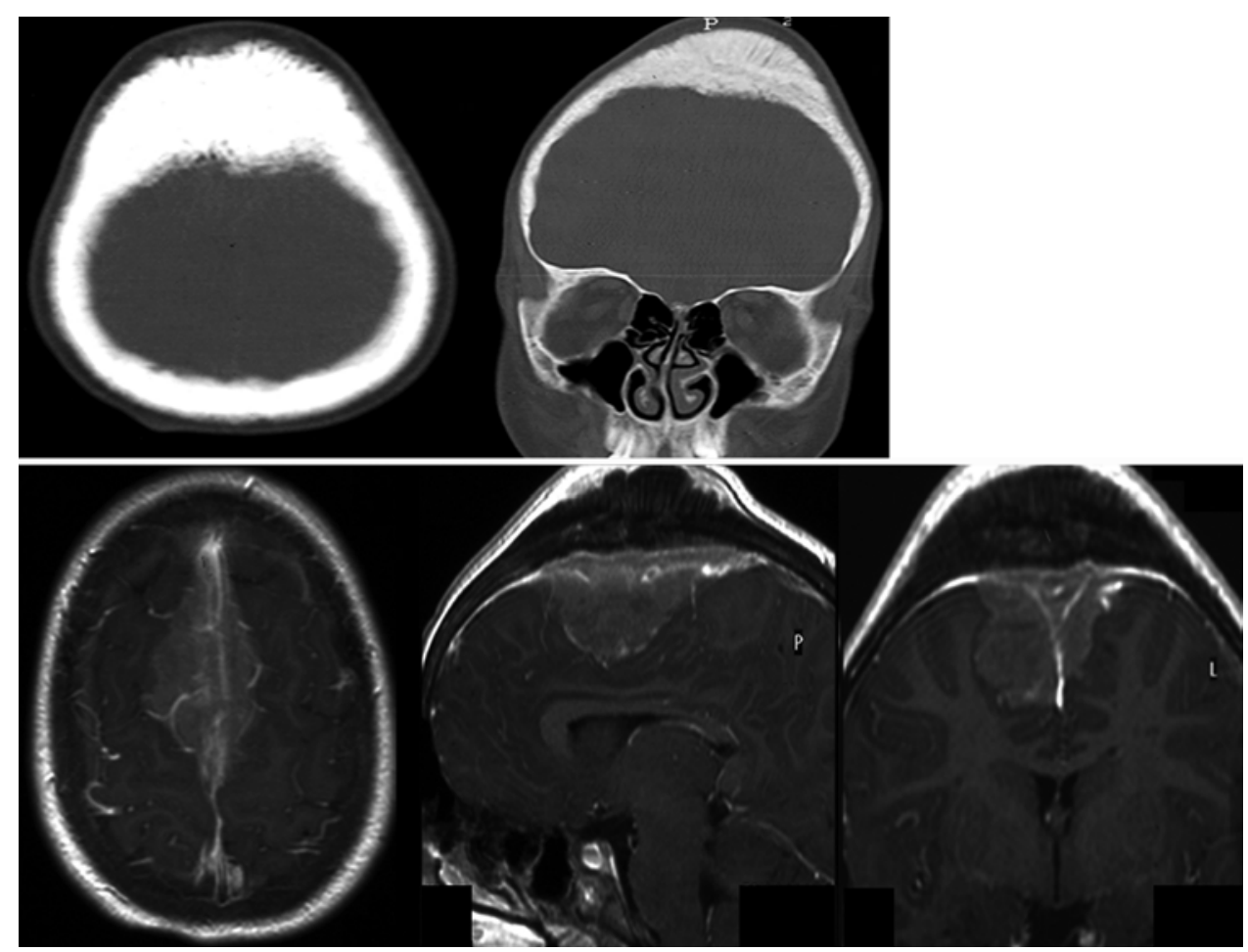

FIG. 1. Case 1. Preoperative CT (upper row) and MR images (lower row) of a 140-month-old patient affected by a falcine meningioma with hyperostotic deformation of the skull.

a significant patient benefit, compared with those patients who underwent autologous bone cranioplasty ${ }^{11}$ and consequently can be reasonably considered the gold standard cranial defect repair method when the native bone flap is unavailable. To produce a custom-made prefabricated PMMA prosthesis (such as in our patients) manufactured using CAD/CAM, a preoperative, transversal, 1-mm spiral CT scan with $3 \mathrm{D}$ reconstruction of the cranium has to be performed before surgery. Each implant then undergoes a sterilization process. ${ }^{16}$ In addition to the significant advantage of improving the cosmetic result (mostly in large skull defects), custom-made cranioplasty implantation implies a shorter operative time, a positive effect on the healing process, less invasiveness and low bleeding risk, fewer infectious complications, no donor site morbidity from the use of allografts, and faster recuperation compared with intraoperatively molded cranioplasty surgery. In addition, in the case of infection or early trauma, the customized implant may be easily remanufactured on the preexisting model. ${ }^{6,15,18,19,21}$ Application of the custom-made technique does, however, have a few disadvantages. First, it is relatively expensive: it costs approximately 5 times more than a noncustomized implant with the same material. Second, the problem of temporal muscle atrophy after a craniectomy also persists using a custom-made cranioplasty implant, which causes some asymmetry in the temporal regions. Third, custom manufacturing of a prefabricated PMMA prosthesis is very time consuming. ${ }^{12}$ While in adult patients the main determinants of material choice are biocompatibility and cosmetic results, in pediatric patients a third concern is the continuing skull growth with age, especially in young children. The major skull growth occurs in the first 2 years, achieving about $84 \%$ of the adult size, with a strong deceleration after that age. Even

TABLE 2. Five questions asked to assess how the patient (or parent, in very young patients) judged the aesthetic result of the procedure*

1. Please estimate the size of your implant (small/medium/large) $\dagger$

2. Choose one of the following statements, which best describes your satisfaction with the aesthetic result of cranioplasty:

a. I do not accept the aesthetic result after cranioplasty \& would like to improve the appearance with another surgical intervention

b. I am not satisfied with the aesthetic result

c. I am satisfied with the aesthetic result

d. I am very satisfied with the aesthetic result \& think that the cranioplasty does not impair my appearance at all

3. If you are dissatisfied, please indicate the reason for your dissatisfaction: e.g., dents, bulges, scars, or bulging of bone edges

4. Did your grade of satisfaction change over time after cranioplasty?

5. Did you have any medical complications after cranioplasty?

\footnotetext{
* As proposed by Fischer et al. ${ }^{8}$

$\dagger$ Implant size was assessed objectively from radiological images and postoperative treatment from patient records. The slice of greatest cross-sectional area of the defect was chosen for size analysis: small, medium, and large defects were defined as $\leq 50 \mathrm{~cm}^{2}, 50-100 \mathrm{~cm}^{2}$, and $\geq 100 \mathrm{~cm}^{2}$, respectively.
} 

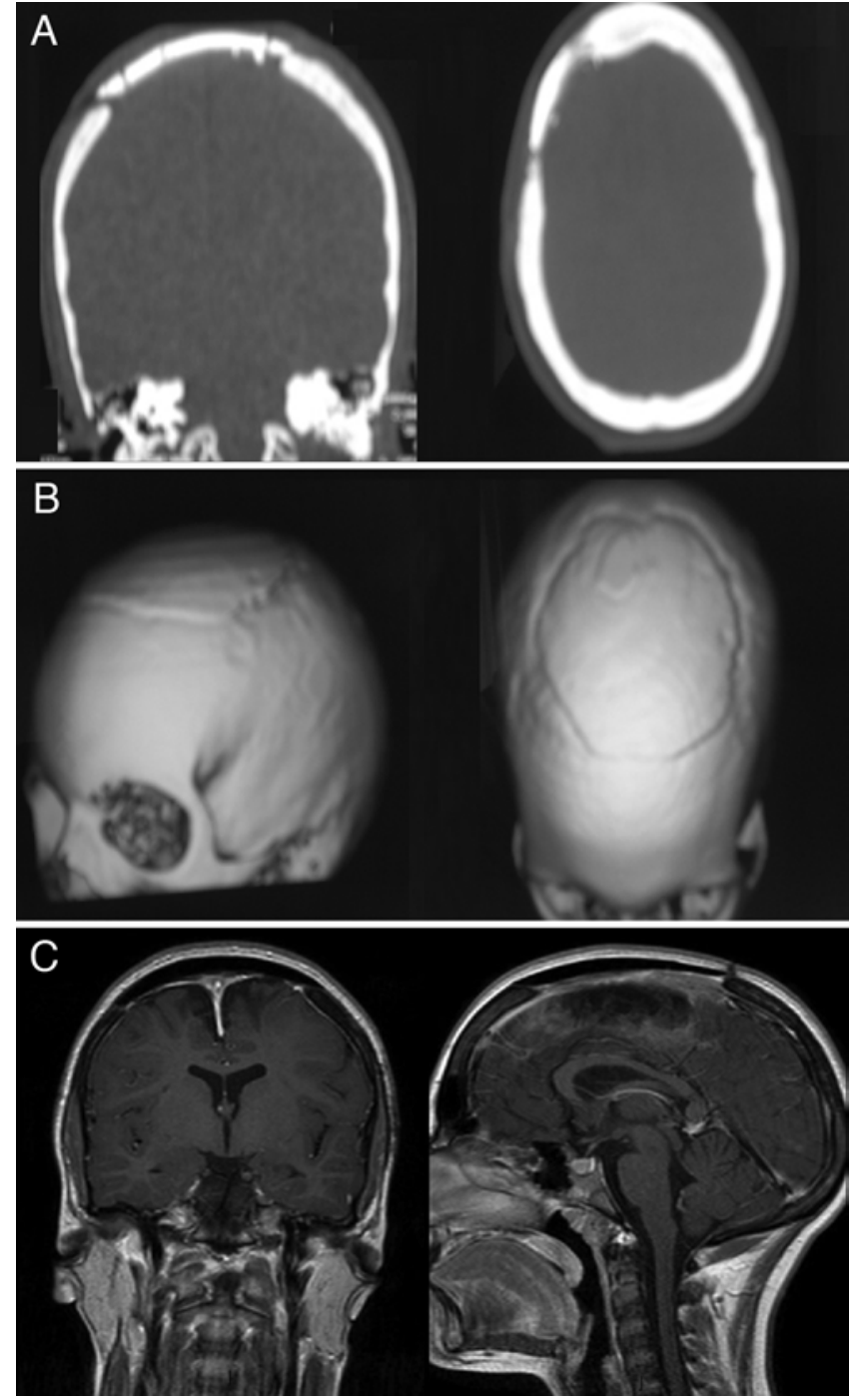

FIG. 2. Case 1. Postoperative CT scan (A) with 3D reconstruction (B) and MR images (C) 3 months after custom-made prosthesis implantation.

in the youngest patients we did not encounter a lack of ability of the prosthesis (made of nonporous PMMA) to become integrated over time, consistent with the growth of the pediatric skeleton. Porous PMMA is a modification of traditional PMMA that further improves this aspect, with its particular architecture allowing ingrowth of native tissue, resulting in a better fixation of the prosthesis. The 3D pore structure serves as an effective "scaffold" for the attachment of osteoprogenitor cells, and as a substrate for deposition of new extracellular matrix material. ${ }^{13}$ Acrylic cranioplasty is generally well tolerated in the adult population, despite an overall complication rate ranging between $5 \%$ and $25 \%$ and an infection rate of $5 \%-20 \%$ in different series. ${ }^{4,5,14}$ Conversely, hydroxyapatite cranioplasty was found to have the highest complication rate, mostly due to infection and material exposure.

When the native bone flap (universally accepted as the preferred option in pediatric patients) is unavailable, our choice of prosthetic material is PMMA; in addition to the
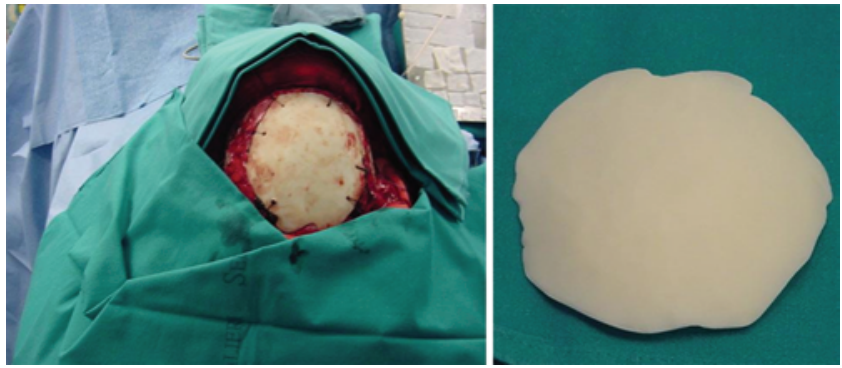

FIG. 3. Case 1. Intraoperative images at the age of 148 months, including the custom-made prosthesis before implantation (right) and how it perfectly fits to the skull defect (left). Figure is available in color online only.

above-mentioned explanation, we prefer it for many other reasons: it is one of the most biocompatible alloplastic materials currently available, with a low rate of foreign body reaction, and provides adequate protection for the underlying neural tissues, comparable to that of native osseous tissue. Furthermore, the custom-made technique offers important advantages, such as an implant that perfectly fits to the bone defect, the avoidance of exposing intracranial tissue to the heat of polymerization, the absence of monomer residue and dust produced during intraoperative molding, and easy remanufacturing on the preexisting model in cases of infection or early trauma. In addition, we determined the already mentioned shorter operative time to be of particular importance in children due to decreased intraoperative blood loss.

In our patient series the choice of implant material was evaluated on a case-by-case basis and discussed with the parents, who were informed about the features, benefits, and risks of the available materials. None of the procedures we performed caused symptomatic foreign body reactions, nor an infection rate. In addition to the intrinsic porus architecture of PMMA, we believe that the surgical filling of the prosthesis with periosteal tissue may help future bone growth as a "scaffold" for the osseous margins of the cranial gap. The mean follow-up duration time was 55.7 months, with two of the longest follow-up durations in the second- and third-youngest patients (10 and 14 months old, respectively). As reported in the questionnaire, these 2 patients did not experience any complications or residual skull defects, with a high level of cosmetic satisfaction.

\section{Conclusions}

A large skull defect mandates subsequent cranioplasty. This procedure is full of possible complications. Our choice of implanting a custom-made PMMA prosthesis was accurately discussed with the parents when the native bone flap was unavailable. In our series, use of PMMA resulted in an extremely low complication rate and the custom-made technique was associated with an excellent grade of patient or parent satisfaction on long-term follow-up.

\section{Acknowledgements}

We are grateful to Dr. A. Rossi for his contribution and the images provided. 


\section{References}

1. Aydin S, Kucukyuruk B, Abuzayed B, Aydin S, Sanus GZ: Cranioplasty: Review of materials and techniques. J Neurosci Rural Pract 2:162-167, 2011

2. Azmi A, Latiff AZ, Johari A: Methyl methacrylate cranioplasty. Med J Malaysia 59:418-421, 2004

3. Baumeister S, Peek A, Friedman A, Levin LS, Marcus JR: Management of postneurosurgical bone flap loss caused by infection. Plast Reconstr Surg 122:195e-208e, 2008

4. Blum KS, Schneider SJ, Rosenthal AD: Methyl methacrylate cranioplasty in children: long-term results. Pediatr Neurosurg 26:33-35, 1997

5. Bruens ML, Pieterman H, de Wijn JR, Vaandrager JM: Porous polymethylmethacrylate as bone substitute in the craniofacial area. J Craniofac Surg 14:63-68, 2003

6. Dean D, Min KJ, Bond A: Computer aided design of largeformat prefabricated cranial plates. J Craniofac Surg 14:819-832, 2003

7. Eppley BL: Biomechanical testing of alloplastic PMMA cranioplasty materials. J Craniofac Surg 16:140-143, 2005

8. Fischer CM, Burkhardt JK, Sarnthein J, Bernays RL, Bozinov O: Aesthetic outcome in patients after polymethylmethacrylate (PMMA) cranioplasty-a questionnaire-based single-centre study. Neurol Res 34:281-285, 2012

9. Flannery T, McConnell RS: Cranioplasty: why throw the bone flap out? Br J Neurosurg 15:518-520, 2001

10. Gao LL, Rogers GF, Clune JE, Proctor MR, Meara JG, Mulliken JB, et al: Autologous cranial particulate bone grafting reduces the frequency of osseous defects after cranial expansion. J Craniofac Surg 21:318-322, 2010

11. Gilardino MS, Karunanayake M, Al-Humsi T, Izadpanah A, Al-Ajmi H, Marcoux J, et al: A comparison and cost analysis of cranioplasty techniques: autologous bone versus custom computer-generated implants. J Craniofac Surg 26:113-117, 2015

12. Lee SC, Wu CT, Lee ST, Chen PJ: Cranioplasty using polymethyl methacrylate prostheses. J Clin Neurosci 16:56-63, 2009

13. Menderes A, Baytekin C, Topcu A, Yilmaz M, Barutcu A: Craniofacial reconstruction with high-density porous polyethylene implants. J Craniofac Surg 15:719-724, 2004

14. Moreira-Gonzalez A, Jackson IT, Miyawaki T, Barakat K,
DiNick V: Clinical outcome in cranioplasty: critical review in long-term follow-up. J Craniofac Surg 14:144-153, 2003

15. Rotaru H, Baciut M, Stan H, Bran S, Chezan H, Iosif A, et al: Silicone rubber mould cast polyethylmethacrylate-hydroxyapatite plate used for repairing a large skull defect. J Craniomaxillofac Surg 34:242-246, 2006

16. Rotaru H, Stan H, Florian IS, Schumacher R, Park YT, Kim SG, et al: Cranioplasty with custom-made implants: analyzing the cases of 10 patients. J Oral Maxillofac Surg 70:e169-e176, 2012

17. Sanan A, Haines SJ: Repairing holes in the head: a history of cranioplasty. Neurosurgery 40:588-603, 1997

18. Solaro P, Pierangeli E, Pizzoni C, Boffi P, Scalese G: From computerized tomography data processing to rapid manufacturing of custom-made prostheses for cranioplasty. Case report. J Neurosurg Sci 52:113-116, 2008

19. van Putten MC Jr, Yamada S: Alloplastic cranial implants made from computed tomographic scan-generated casts. J Prosthet Dent 68:103-108, 1992

20. Weber RS, Kearns DB, Smith RJ: Split calvarium cranioplasty. Arch Otolaryngol Head Neck Surg 113:84-89, 1987

21. Wulf J, Busch LC, Golz T, Knopp U, Giese A, Ssenyonjo H, et al: CAD generated mold for preoperative implant fabrication in cranioplasty. Stud Health Technol Inform 111:608610,2005

\section{Disclosures}

The authors report no conflict of interest concerning the materials or methods used in this study or the findings specified in this paper.

\section{Author Contributions}

Conception and design: Fiaschi, Pavanello, Imperato, Dallolio, Piatelli. Acquisition of data: Consales. Analysis and interpretation of data: Consales. Drafting the article: Accogli, Capra, Cama. Study supervision: Capra.

\section{Correspondence}

Pietro Fiaschi, Department of Neurosurgery, San Martino - IST University Hospital (IRCCS), Largo Rosanna Benzi 10, Genoa 16132, Italy. email: pietro.fiaschi@alice.it. 